\title{
Biocompatible Nutmeg Oil-Loaded Nanoemulsion as Phyto-Repellent
}

\author{
Masturah Mohd Narawi ${ }^{1}$, Hock Ing Chiu ${ }^{1}$, Yoke Keong Yong ${ }^{2}$, \\ Nur Nadhirah Mohamad Zain ${ }^{1}$, Muggundha Raoov Ramachandran ${ }^{3}$, Chau Ling Tham ${ }^{4}$, \\ Siti Fatimah Samsurrijal ${ }^{5}$ and Vuanghao Lim $^{1 *}$ \\ ${ }^{1}$ Integrative Medicine Cluster, Advanced Medical and Dental Institute, Universiti Sains Malaysia, Penang, Malaysia, \\ ${ }^{2}$ Department of Human Anatomy, Faculty of Medicine and Health Sciences, Universiti Putra Malaysia, Serdang, Malaysia, \\ ${ }^{3}$ Department of Chemistry, Faculty of Science, Universiti Malaya, Kuala Lumpur, Malaysia, ${ }^{4}$ Department of Biomedical \\ Science, Faculty of Medicine and Health Sciences, Universiti Putra Malaysia, Serdang, Malaysia, ${ }^{5}$ Craniofacial \\ and Biomaterial Sciences Cluster, Advanced Medical and Dental Institute, Universiti Sains Malaysia, Penang, Malaysia
}

Plant essential oils are widely used in perfumes and insect repellent products. However, due to the high volatility of the constituents in essential oils, their efficacy as a repellent product is less effective than that of synthetic compounds. Using a nanoemulsion as a carrier is one way to overcome this disadvantage of essential oils. Nutmeg oil-loaded nanoemulsion (NT) was prepared using a high speed homogenizer and sonicator with varying amounts of surfactant, glycerol, and distilled water. Using a phase diagram, different formulations were tested for their droplet size and insect repellent activity. The nanoemulsion containing $6.25 \%$ surfactant and $91.25 \%$ glycerol (NT 6) had the highest percentage of protection (87.81\%) in terms of repellent activity among the formulations tested for the $8 \mathrm{~h}$ duration of the experiment. The droplet size of NT 6 was $217.4 \mathrm{~nm}$, and its polydispersity index (PDI) was 0.248 . The zeta potential value was $-44.2 \mathrm{mV}$, and the viscosity was $2.49 \mathrm{~Pa}$.s at pH 5.6. The in vitro release profile was $71.5 \%$. When the cytotoxicity of NT 6 at $400 \mu \mathrm{g} / \mathrm{mL}$ was tested using the MTS assay, cell viability was $97.38 \%$. Physical appearance and stability of the nanoemulsion improved with the addition of glycerol as a co-solvent. In summary, a nutmeg oil-loaded nanoemulsion was successfully formulated and its controlled release of the essential oil showed mosquito repellent activity, thus eliminating the disadvantages of essential oils.

Keywords: nutmeg oil, repellent activity, in vitro release, nanoemulsion, Aedes aegypti

\section{INTRODUCTION}

Zika virus recently spread to Malaysia, with six cases reported in September 2016 (Subramaniam, 2016). Zika virus, which is a mosquito-borne flavivirus that is closely related to the dengue virus, first appeared in Brazil and then spread to countries in Latin America (Subramaniam, 2016). Other mosquito-borne diseases such as yellow fever, dengue, and chikungunya also have become major health problems in tropical and subtropical countries (Adeniran and Fabiyi, 2012; Gupta et al., 2013). Hence, the use of insect repellent products is essential to prevent these diseases (Rocha-Filho et al., 2014). N, N-diethyl-3-methylbenzamide (DEET) is the synthetic main active ingredient in commercial mosquito repellent products, and it has excellent repellency against a wide range of 
insects (Hang Chio and Yang, 2008). However, DEET poses health risks such as developmental toxicity in animals and environment (Iyer and Makris, 2010; Solomon et al., 2012).

With increased awareness of maintaining a green environment, biodegradable sources of mosquito repellent are widely promoted to replace chemical synthetic products that can have adverse effects on users (Maji and Hussain, 2009). Among available natural sources, essential oils from plants (Teng and Chen, 2017) are the preferred natural insect repellent because they contain rich sources of bioactive compounds, biodegrade to non-toxic products, and have less toxic on non-target organisms and the environment (Govindarajan, 2010; Lim et al., 2012; Assi et al., 2017). Plant essential oils are efficient insect repellents and provide direct protection to the user (Azeem et al., 2019). Although plant essential oils have been used in insect repellent products, their effectiveness is not significant (Bissinger and Roe, 2010). One possible reason could be that these products are characterized by uncontrolled release of the essential oil (such as, they either release too little or too much, with shorter duration of protection) (Solomon et al., 2012).

One potential way to solve the uncontrolled release problem is to encapsulate essential oils in nanoemulsions (Chen et al., 2020 b). Preparation of a nanoemulsion involves mixing of two non-miscible liquids, such as oil and water, to produce spherical droplets with size ranging from 20 to $500 \mathrm{~nm}$ (San MartinGonzález et al., 2009). Their appearance is either transparent or slightly opaque (Sugumar et al., 2014). An additional constituent in nanoemulsions is surfactant, which acts as an emulsifying agent to decrease the interfacial tension between oil and water (Musa et al., 2013). Its presence prevents phase separation upon dispersion of the two immiscible liquids (Devarajan and Ravichandran, 2011). The stability of a nanoemulsion depends on its preparation. High energy emulsification provides intense disruptive forces to break up the mixture of oil, water, and surfactant into small droplets (Musa et al., 2013). Low energy emulsification involves the phase inversion method (Pant et al., 2014).

In this study, nutmeg oil-loaded nanoemulsion (NTs) systems were developed using glycerol, Montanov ${ }^{\circledR} 82$ (non-ionic surfactant), and deionized water. We aim to investigate the effect of high energy emulsification of the system consisting nutmeg oil, together with physicochemical characteristics, the release study and mosquito repellent activity of the nutmeg oil-loaded nanoemulsion.

\section{MATERIALS AND METHODS}

\section{Essential Oil and Standards}

The essential oil, namely nutmeg oil (Myristica fragrans) was purchased from Imeltech Sdn. Bhd (Kuala Lumpur, Malaysia) with in-house code no. MF-004 (Batch no. NMO7956FT) and stored at the Herbarium Unit, Integrative Medicine Cluster, Advanced Medical and Dental Institute (IPPT). $\alpha$-pinene (Batch no. SHBB7538V, Sigma-Aldrich, St Louis, United States), safrole (Batch no. BCBH2795V, Sigma-Aldrich, Shanghai, China), and terpinen-4-ol (Batch no. BCBF8537V, Sigma-Aldrich, Madrid, Spain) were used as standards for GCMS analysis.

\section{Animal and Test Organisms}

Sprague Dawley (SD) rats were purchased from the Animal Research and Service Centre, Universiti Sains Malaysia (USM). Female Aedes (Ae). aegypti and DEET were supplied by the Vector Control Research Unit (VCRU), USM.

\section{Nutmeg Oil-Loaded Nanoemulsions}

The essential oil-loaded nanoemulsion method was adapted from Sakulku et al. (2009) with slight modifications. Briefly, a phase diagram of surfactant, co-solvent, and water representing an apex triangle was plotted. Ternary mixtures with varying concentrations of surfactant (Montanov ${ }^{\circledR}$ 82), co-solvent (glycerol), and double distilled water were prepared with a fixed nutmeg oil concentration $(20 \% \mathrm{v} / \mathrm{v})$. For each mixture, the total surfactant, co-solvent, and water summed to $100 \%$. The mixture was emulsified using a high speed homogenizer (WT 130 handheld homogenizer, Medigene, Selangor, Malaysia) at 18,000 rpm for $3 \mathrm{~min}$. The formulation then was sonicated for $30 \mathrm{~min}$ using ultrasonicator cleaner (WUC-A10H, Wise Clean, Sonic Wise, California, United States) to obtain a submicron emulsion (Ragelle et al., 2012). Lastly, the formulation was centrifuged at 10,000 rpm for $15 \mathrm{~min}$ (Supermini Centrifuge, Hangzhou Allsheng Instruments CO., Ltd., Zhejiang Province, China). Visual observation was made immediately after centrifugation. Formulations with phase separation were rejected, whereas those without phase separation were chosen for particle size analysis. The desirable particle size was between 100 and $500 \mathrm{~nm}$. The produced NTs were stored at $25^{\circ} \mathrm{C}$ until further use.

\section{Droplet Size and PDI}

The particle size and PDI of the NTs were measured using the dynamic light scattering (DLS) technique at an angle of $173^{\circ}$ and temperature of $25^{\circ} \mathrm{C}$. This process was carried out using Zeta Nano-ZS apparatus (Malvern Instruments, Malvern, United Kingdom). Each NT sample was diluted with double distilled water until it reached the desired concentration, and all diluted samples were kept at a count rate of $150-300 \mathrm{k}$. Measurements were performed in triplicates.

\section{Mosquito Repellent Activity of NTs Animal Ethics and Preparation of Animals}

All animal procedures used were in strict accordance with animal care protocols, and all experimental protocols were approved by the Universiti Sains Malaysia Animal Ethics Committee [USM/Animal Ethics Approval/2013/(85) (441)]. SD rats (aged 8-10 weeks) were used for the insect repellent tests. The rats were kept at the Animal Research Facility, IPPT, USM under standard laboratory conditions for animals [temperature: $25 \pm 2{ }^{\circ} \mathrm{C}$; relative humidity $(\mathrm{RH}): 55 \pm 5 \%$ ], with food and water provided and bedding replacement three times per week (Lim et al., 2012).

\section{Test Organisms}

The mosquitoes (Ae. Aegypti) were cultivated in the laboratory at constant temperature of $25-30^{\circ} \mathrm{C}$ and $80-90 \% \mathrm{RH}$ at the VCRU, 
USM. A Whatman (Maidstone, United Kingdom) filter paper was placed in a Petri dish filled with chlorine-free water, which then was placed in an adult female mosquito's cage. After eggs were laid, the Petri dish was removed and the eggs were allowed to hatch within $24 \mathrm{~h}$. The newly hatched larvae were transferred into a rearing tray containing chlorine-free water and fed with a mixture of $\operatorname{dog}$ food, beef liver, yeast, and milk powder in the ratio of $2: 1: 1: 1 \mathrm{w} / \mathrm{w} / \mathrm{w} / \mathrm{w}$. Larvae were fed every day until pupation. At this stage, the pupae were separated from larvae and placed in a plastic cup with chlorine-free water in a mosquito cage. The plastic cup was removed from the cage when all adults had emerged. The adult mosquitoes were fed with vitamin B complex solution and $10 \%$ of sugar solution. Female adult mosquitoes of 5-7 days old were starved of blood for $24 \mathrm{~h}$ before being used in the repellent activity test.

\section{Repellent Activity}

The mosquito repellent tests of the selected NTs were conducted using female mosquitoes and rats as the blood donor. This method was adapted from Oshaghi et al. (2003) with slight modification. A rat was placed in a customized cage. The rat's upper body (around $5 \times 5 \mathrm{~cm}$ ) was cleaned using ethanol and dried for 1-2 min before applying the NT. Approximately $1 \mathrm{~mL}$ of the NT was applied to the cleaned rat's body. Another rat was treated with DEET (positive control), and another with liquid paraffin (negative control). Each rat was then placed in a mosquito cage containing 50 female Ae. aegypti mosquitoes for first $10 \mathrm{~min}$ of every hour for a total of $8 \mathrm{~h}$. The number of mosquitoes that landed on the rat (10 s) within each $10 \mathrm{~min}$ interval was counted and compared to the controls. Each test was performed in triplicates with a new batch of mosquitoes. The numbers of landings in treated and control tests (positive and negative) were recorded, and the mean percentage protection from mosquito landing was calculated. The percentage protection is defined as the average number of bites received by the subject in each test and was calculated using equation (1):

$$
\text { Percentage protection }=\frac{(50-\mathrm{NL})}{50} \times 100
$$

Where $50=$ number of mosquitoes in the cage and $\mathrm{NL}=$ number of landings.

\section{Characterizations of NTs Zeta Potential}

The electrophoretic mobility and surface charge of each NT were measured by the frequency shift of scattered light at a $12^{\circ}$ scattering angle using the Zeta Nano-ZS apparatus. Measurements were performed in triplicates.

\section{Transmission Electron Microscope (TEM) Analysis}

Visualization of the morphology and structure of the NTs was carried out by TEM analysis (Ghozali et al., 2015). A drop ( $1 \mu \mathrm{L})$ of NT diluted with deionized water (1:200) was placed on a 300 mesh copper grid and left for $1 \mathrm{~min}$. The excess liquid was drawn off with Whatman filter paper. The grid was kept inverted and a drop of $2 \%(\mathrm{w} / \mathrm{w})$ phosphotungstic acid (PTA) was applied to the grid for $10 \mathrm{~s}$ to negatively stain the sample. Excess PTA was removed by absorption on a Whatman filter paper. The grid was analyzed using a TEM Philips CM12 with Docu version 3.2 image analysis (Lim et al., 2013; Ayub et al., 2019).

\section{Viscosity and Flow Analysis}

Viscosity measurement and flow analysis of the NTs were performed using a dynamic shear rheometer (Rheologica Viscotech, Tarragona, Spain). A $40 \mathrm{~mm}$ diameter of parallel plate geometry was attached to the instrument and calibrated with a gap width of $1 \mathrm{~mm}$. Next, $1500 \mu \mathrm{L}$ of the NT were pipetted onto the surface of the rheometer with the absence of bubbles. The rheometer was run with the shear rate ranging from 0.1 to $1000 \mathrm{~s}^{-1}$ for $5 \mathrm{~min}$, and the rate then was reduced from 1000 to $0.1 \mathrm{~s}^{-1}$ over the course of $5 \mathrm{~min}$.

$\mathrm{pH}$

The $\mathrm{pH}$ values of the NTs were determined directly using a calibrated $\mathrm{pH}$ meter (LIDA 92 series, Eutech Instruments Pte Ltd., Ayer Rajah Crescent, Singapore) at room temperature. The analyses were performed in triplicates.

\section{Release Study \\ In vitro Release of Nutmeg Oil}

The release study was conducted using Franz-type diffusion cells (Carbone et al., 2014). First, $1 \mathrm{~mL}$ of NT was loaded on a cellulose acetate membrane with $0.2 \mu \mathrm{m}$ pore size and $25 \mathrm{~mm}$ diameter. Prior to sample loading, the membrane was soaked in isopropyl myristate for $1 \mathrm{~h}$ to mimic the lipophilic barrier of the stratum corneum. Next, the membrane was mounted on top of the cells with $25 \mathrm{~mL}$ of water-ethanol (50:50) in the receiving compartment. This was to allow the "sink" condition and sustain essential oil solubilization. This compartment was constantly stirred at $700 \mathrm{rpm}$ at $32^{\circ} \mathrm{C}$ and equilibrated for $30 \mathrm{~min}$ before collecting the first sample. An aliquot of receptor medium $(1 \mathrm{~mL})$ was collected at $0 \mathrm{~min}, 30 \mathrm{~min}$, and then every hour thereafter for $24 \mathrm{~h}$ during the study. At each sampling time point, the system was replenished with the same volume of fresh, preheated receptor medium. The collected samples were analyzed by gas chromatography-mass spectrometry (GC-MS) after extraction with hexane. This experiment was performed in triplicates. The essential oil release kinetics from NTs was investigated by fitting the release data into Higuchi's model, which can be expressed as:

$$
\mathrm{Q} t=k t^{0.5}
$$

where $Q t$ is the percent of essential oil released at a given time $(t)$ and $k$ is the release rate.

\section{GC-MS Analysis}

The collected samples from the release study were extracted using the liquid-liquid extraction technique for GC-MS analysis (Donsì et al., 2012). First, $1 \mathrm{~mL}$ of sample was dissolved in $5 \mathrm{~mL}$ of $\mathrm{n}$-hexane and vortexed vigorously for $1 \mathrm{~min}$. Sodium sulfate was added to the separated organic phase to remove the residual water. The GC-MS method was adapted from Lim et al. (2019). For sample analysis, $1 \mu \mathrm{L}$ of diluted extracted sample in n-hexane 
(1:1000) was auto injected in the splitless mode. The constituents in the essential oil were identified by comparison with the National Institute of Standard and Technology mass spectral library and presented as relative percentage of the total peak (Tan et al., 2014; Lim et al., 2015).

\section{Cytotoxicity Assay Cell Preparation}

L929 cells (mouse fibroblast cells) were obtained from the American Type Culture Collection (ATCC). The preheated $\left(37^{\circ} \mathrm{C}\right)$ culture vessel and medium were placed in a biosafety cabinet class II (ESCO Labculture ${ }^{\circledR}$, Esco Micro Pte Ltd., Changi South Street, Singapore). The morphology of the cells was checked using an inverted microscope (CKX41 SF, Olympus, Tokyo, Japan). L929 cells were seeded in $75 \mathrm{~cm}^{2}$ culture flasks that contained Dulbecco's modified eagle medium supplemented with $15 \%$ phosphate buffered saline (PBS), $5 \mathrm{~mL}$ penicillin streptomycin, and $5 \mathrm{~mL} \mathrm{L-glutamine.} \mathrm{Next,} \mathrm{the} \mathrm{medium} \mathrm{was}$ aspirated and cells were washed twice with $5 \mathrm{~mL}$ PBS. Trypsin $(5 \mathrm{~mL})$ was added to disaggregate the cells, which then were incubated in a $\mathrm{CO}_{2}$ incubator (Heraeus BB15, Thermo Scientific, Massachusetts, United States) at $37^{\circ} \mathrm{C}$ for $15 \mathrm{~min}$. Then, $10 \mathrm{~mL}$ of warm medium were added to the cells after detachment to stop the trypsinization and to disperse the cells. The cells were centrifuged (Heraeus Megafuge 16 centrifuge, Thermo Scientific) at $1000 \mathrm{rpm}$ for $5 \mathrm{~min}$, and the supernatant was aspirated. Lastly, $5 \mathrm{~mL}$ of fresh warm medium was added and pipetted up and down with the pellet, then $50 \mu \mathrm{L}$ of the cells were added to $50 \mu \mathrm{L}$ of trypan blue to calculate the cell using hemocytometer (Yakop et al., 2018).

\section{Sample Dilution}

For cell treatment, selected NT formulations were diluted with deionized distilled water in concentrations ranging from 50 to $400 \mathrm{mg} / \mathrm{mL}$. The same procedure was repeated for DEET.

\section{3-(4, 5-Dimethylthiazol-2-yl)-5-(3-Carboxymethoxy- phenyl)-2-(4Sulfophenyl)-2H-Tetrazolium (MTS) Assay}

L929 cells were seeded at $3 \times 10^{3}$ cells $/ \mathrm{mL}$ into 96 -well plates containing $100 \mu \mathrm{L}$ of medium (Hanan et al., 2018; Poobalan et al., 2018). Next, $50 \mu \mathrm{L}$ of diluted NT and DEET at different concentrations were added to the cells. Cells were incubated for $48 \mathrm{~h}$ with untreated cells as the control. Each plate was then treated with $20 \mu \mathrm{L}$ of MTS reagent, and absorbance was read at $490 \mathrm{~nm}$ after $4 \mathrm{~h}$ using a microplate reader (FLUOstar Omega, BMG LABTECH, Offenbury, Germany). Cell viability (\%) was calculated using the following formula:

$$
\text { Cell viability }(\%)=\frac{O D \text { sample }}{O D \text { control }} \times 100
$$

where $O D$ is the absorbance from the microplate reader.

\section{Thermodynamic Stability Study}

The preliminary stability of the NTs was evaluated at $24 \mathrm{~h}$ by centrifuging at $15,000 \mathrm{rpm}$ for $15 \mathrm{~min}$. Samples showing layer separation were eliminated. Samples without layer separation were stored at $25 \pm 2^{\circ} \mathrm{C}, 60 \pm 2^{\circ} \mathrm{C}$, and $4 \pm 2^{\circ} \mathrm{C}$. Droplet size and $\mathrm{pH}$ were measured at $1,30,60$, and $90 \mathrm{~d}$. The experiment was performed in triplicates.

\section{Statistical Analysis}

Values were expressed as mean \pm standard deviation (SD). Differences among samples were examined using one-way analysis of variance. A difference was considered to be statistically significant at $p<0.05$.

\section{RESULTS AND DISCUSSION}

\section{Phase Diagram for NTs}

A phase diagram of ternary mixtures with surfactant (Montanov ${ }^{\circledR}$ 82), co-solvent (glycerol), and double distilled water with nutmeg oil at a fixed concentration of $20 \% \mathrm{v} / \mathrm{v}$ was constructed (Figure 1). Each apex on the triangle representing the ternary system represents $100 \%$ of the component at that apex. The amount of surfactant used in the formulation ranged from 3.75 to $56.25 \%$, that of glycerol ranged from 0.0 to $93.75 \%$, and that of double distilled water ranged from 3.75 to $93.75 \%$. In total, 296 formulations were constructed on the phase diagram. Visual observation was made immediately after the preparation of each formulation. Formulations that appeared as one phase were selected, and their average particle size was determined by the DLS technique using the Zeta Nano-ZS apparatus. Formulations with droplet size of $\leq 500 \mathrm{~nm}$ were selected as NTs for further testing (Pant et al., 2014).

Table 1 shows the composition of the single phase nanoemulsions in the ternary system. NT 13 contained the highest percentage of surfactant (31.25\%) and NTs 11, 14, and 15 had the lowest $(3.75 \%)$. The amount of co-solvent in these NTs ranged from $93.17 \%$ (NT 15) to $15 \%$ (NT 3). NT 1 was formulated with $12.5 \%$ surfactant and $87.50 \%$ water, without any co-solvent.

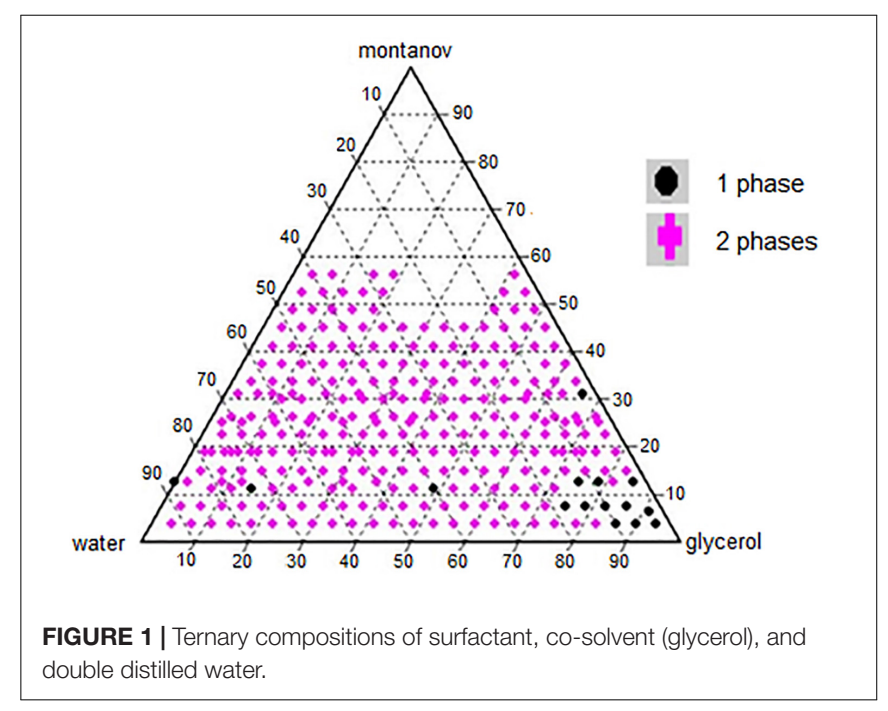


TABLE 1 | Composition of NTs.

\begin{tabular}{lccc}
\hline Sample & $\begin{array}{c}\text { \% (v/v) of surfactant } \\
\text { (Montanov }^{\circledR 8} \mathbf{8 2 )}\end{array}$ & $\begin{array}{c}\text { \% (v/v) of } \\
\text { glycerol }\end{array}$ & $\begin{array}{c}\%(\mathbf{v} / \mathbf{v}) \text { of } \\
\mathbf{H}_{\mathbf{2}} \mathbf{O}\end{array}$ \\
\hline NT 1 & 12.50 & 0.00 & 87.50 \\
NT 2 & 12.50 & 75.00 & 12.50 \\
NT 3 & 11.25 & 15.00 & 73.75 \\
NT 4 & 11.25 & 48.75 & 40.00 \\
NT 5 & 12.50 & 78.75 & 8.75 \\
NT 6 & 6.25 & 91.25 & 2.50 \\
NT 7 & 12.50 & 85.00 & 2.50 \\
NT 8 & 7.50 & 75.00 & 17.50 \\
NT 9 & 7.50 & 78.75 & 13.75 \\
NT 10 & 7.50 & 82.50 & 10.00 \\
NT 11 & 3.75 & 86.25 & 10.00 \\
NT 12 & 7.50 & 86.25 & 6.25 \\
NT 13 & 31.25 & 66.25 & 2.50 \\
NT 14 & 3.75 & 90.00 & 6.25 \\
NT 15 & 3.75 & 93.75 & 2.50 \\
\hline
\end{tabular}

The construction of phase diagram is crucial to determine the single-phase boundary at each percentage of surfactant, cosolvent, and water with a fix percentage of nutmeg oil (20\%) to yield a nanoemulsion in low free energy and thermodynamically spontaneous (Shakeel et al., 2008). The regions of the nanoemulsion in the phase diagram shown in Figure 1 were marked after visual observation of the formulated samples to identify those that were monophasic, clear and transparent mixtures after stirring, sonication, and thermodynamic stability testing (Devarajan and Ravichandran, 2011).

A surfactant or emulsifying agent is important in formulating a nanoemulsion because it reduces interfacial energy between oil and the aqueous phase via formation of a layer around the droplets of the nanoemulsion and it provides a mechanical barrier to coalescence (Kotta et al., 2014). Hence, surfactants added to a water-in-oil system (nutmeg oil, water, and glycerol) increase the aqueous phase concentration due to micelle solubilization. In our study, nutmeg oil was attached to the hydrophobic region of the emulsifier micelle and transferred to the aqueous phase (Donsì et al., 2012). At high concentration of surfactant, smaller droplets of NT are formed, which decreases the interfacial tension between nutmeg oil and the aqueous phase (Wang et al., 2007). Phase separation of a nanoemulsion might occur at low concentration of surfactant due to incomplete coverage of surfactant to oil and aqueous phase (Musa et al., 2013). Therefore, identifying the optimal surfactant concentration was important for solubilizing the oil with micelle solutions with the maximum amount of surfactant at $10 \%$ to the oil ratio (Fernandez et al., 2004). Yuan et al. (2008) reported that the combination of Tween 20-Tween 40 (10\%) and Tween 60$80(6 \%)$ reached a plateau for droplet size of the nanoemulsion. This is because of full coverage by the excessive surfactant in the nanoemulsion system (Yuan et al., 2008). Tang et al. (2012) reported that the minimum droplet size of a nanoemulsion occurred when 5-6\% concentration of Cremophore EL was used; further addition of surfactant led to an increase in droplet size of the nanoemulsion (Tang et al., 2012). In our study, $7.5 \%$ was the maximum surfactant percentage that led to the formation of nano sized droplets with an acceptable PDI value. Once the nutmeg oil in the formulation has reached the saturation level (micelles), any addition of water and surfactant would not further dissolve. Excess free surfactant that is not adsorbed to the oil and aqueous interface would cause flocculation due to the increase of local osmotic pressure; this would cause the surfactants to "flow out" from the intervening liquid between the droplets, which in turn would lead to phase separation of the formulated samples (Jafari et al., 2007).

Glycerol acted as a co-solvent in this system to increase the viscosity of NTs and to decrease the droplet collision frequency (Chanasattru et al., 2007). Glycerol is added to the aqueous phase of a nanoemulsion to modify the bulk physicochemical properties of the formulated samples, such as density, viscosity, refractive index, interfacial tension, optimum curvature, and solubility of the surfactant in the aqueous phase (Saberi et al., 2013). In our study, a high concentration of glycerol led to the nano formation of NTs (Saberi et al., 2013).

\section{Droplet Size and PDI of Formulated NTs}

The 15 formulations with single phase from the phase diagram were selected to determine their droplet size and PDI values using the DLS technique and a Zeta Nano-ZS apparatus. DLS measures the $\mathrm{z}$-average mean of the nanoemulsion (Yuan et al., 2008). Figure 2 shows the average droplet size and PDI of the selected samples. NT 6 exhibited the smallest droplet size (mean diameter $217.4 \mathrm{~nm})$, and NT 13 had the largest droplet size $(516.13 \mathrm{~nm})$. As mentioned earlier, any NT with droplet size $>500 \mathrm{~nm}$ was rejected. Therefore, NT 13 was eliminated from further analysis. Formulations with droplet size in the range of 200 to $300 \mathrm{~nm}$ were NT $7(266.17 \mathrm{~nm})$, NT 8 (299.83 nm), NT 9 (299.13 nm), and NT $11(288.1 \mathrm{~nm})$. The rest of the formulations had droplet sizes between 300 and $400 \mathrm{~nm}$. The appearance of NT 6 was slightly transparent because of its tiny droplet size. Although some of the NTs appeared cloudy, their droplet size was still in the nano range. Salvia-Trujillo et al. (2015) also reported that the droplet size of their nanoemulsion was still in the nano range despite a slightly turbid physical appearance.

The DLS technique measures the Brownian motion of the droplets, which is referred as the intensity-weighted average hydrodynamic diameter of the emulsion. Large droplets move more slowly than small ones. Sufficient dispersion of the nanoemulsion is required to reduce the multiple scattering effect of Brownian motion (Leong et al., 2009). Small droplets have a greater surface area than large droplets, thus more surfactant is needed to cover this greater area (Yuan et al., 2008). For this reason, the droplet size of NTs decreased with increasing percentage of surfactant due to adsorption of high amounts of oil and water. This led to the increased surface area and reduced interfacial energy, which provided the mechanical barrier to coalescence (Carbone et al., 2014).

Polydispersity index is an important measurement of homogeneity and stability of a formulated nanoemulsion. A small value of PDI indicates homogeneity and a narrow distribution of the nanoemulsion system (Sugumar et al., 2014). PDI values 


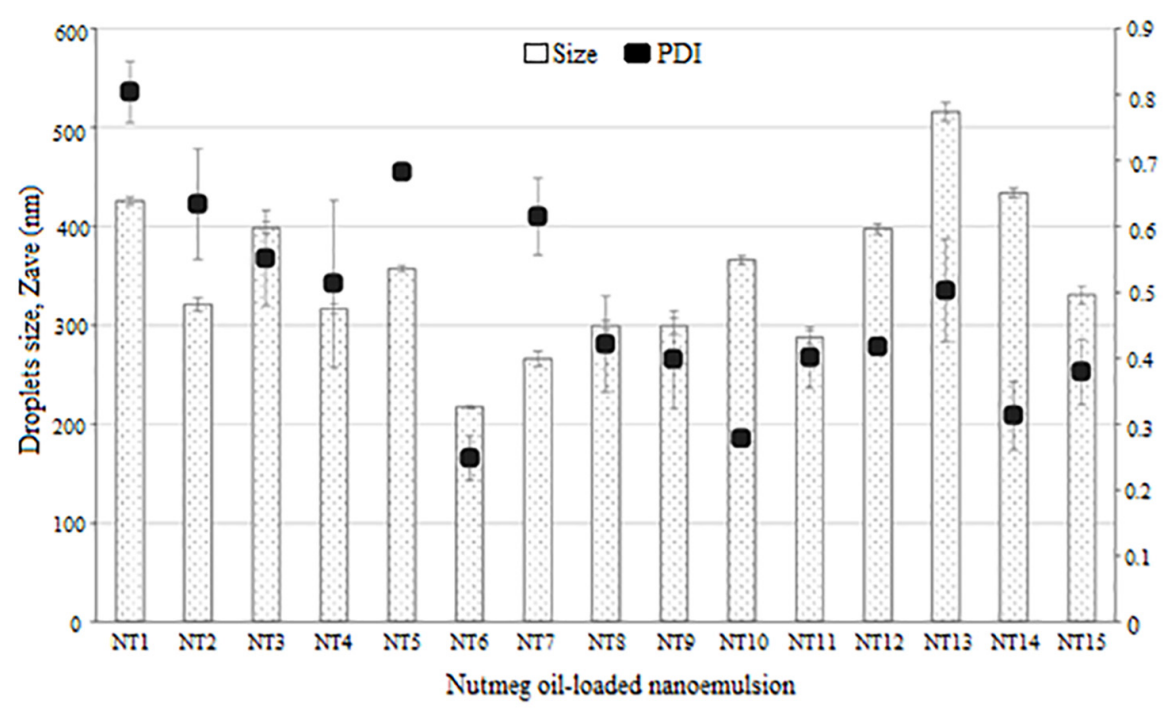

FIGURE 2 | Droplet size and polydispersity index of NTs (mean $\pm \mathrm{SD}, n=3$ ).

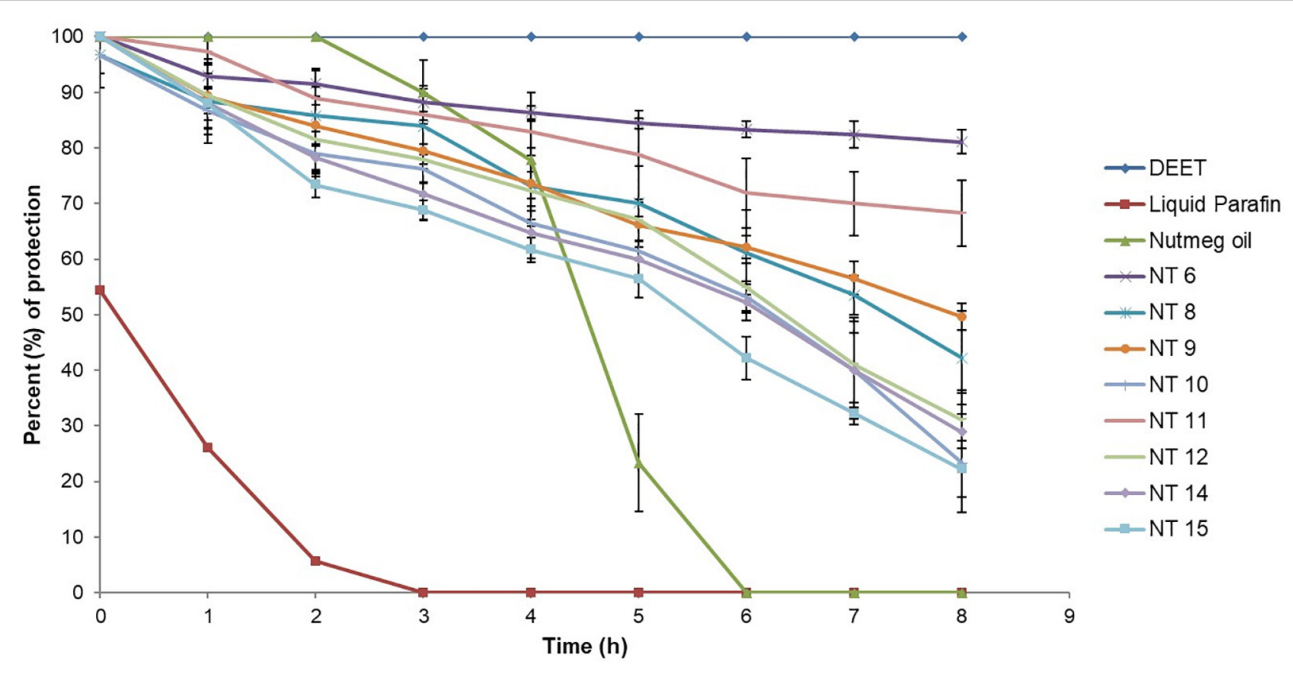

FIGURE 3 | Mosquito repellent activity of controls, nutmeg oil, and selected NTs at hour intervals for the $8 \mathrm{~h}$ repellent test (Mean \pm SD, $n=3$ ).

range from 0 to 1 for width size distribution, where 0 indicates a monodispersed particle and $>0.5$ indicates a broad distribution (Borhade et al., 2012). The formulations with PDI values $<0.5$ were NT 6 (0.248), NT 8 (0.421), NT 9 (0.398), NT 10 (0.278), NT 11 (0.401), NT 12 (0.418), NT 14 (0.313), and NT 15 (0.379). These eight formulations had low PDI values, which indicated they had a similar and narrow size distribution (stable and uniform) (Divsalar et al., 2012). Hence, they were chosen for use in the mosquito repellent test. In contrast, PDI values of NT 1, NT 2, NT 3, NT 4, NT 5, NT 7, and NT 13 were >than 0.5 and thus were eliminated from further study. High PDI values indicate an inhomogeneous and polydispersed distribution (Wissing and Müller, 2002). Polydispersity occurs when both large and small droplets are produced in a nanoemulsion system. When Ostwald ripening occurs, small droplets dissolve into the large droplets, leading to increased droplet size (Wissing and Müller, 2002). This system is unstable, and phase separation occurs in such formulations after $24 \mathrm{~h}$.

\section{Repellent Activity of the Selected NTs}

Based on droplet size and PDI value, NT 6, NT 8, NT 9, NT 10, NT 11, NT 12, NT 14, and NT 15 were chosen for the mosquito repellent studies. These nanoemulsions did not show any phase separation after $24 \mathrm{~h}$, indicating their stability. Figure 3 shows the mosquito repellent activity of the selected NTs at every hour interval throughout the $8 \mathrm{~h}$ repellent test. The mosquito repellent activities of these NTs were compared with those of nutmeg oil, DEET (positive control), and liquid paraffin (negative control). At hour 0, nutmeg oil and NT 6, NT 9, NT 11, NT 12, NT 14, and NT 15 provided full protection (100\%) for the subjects; NT 


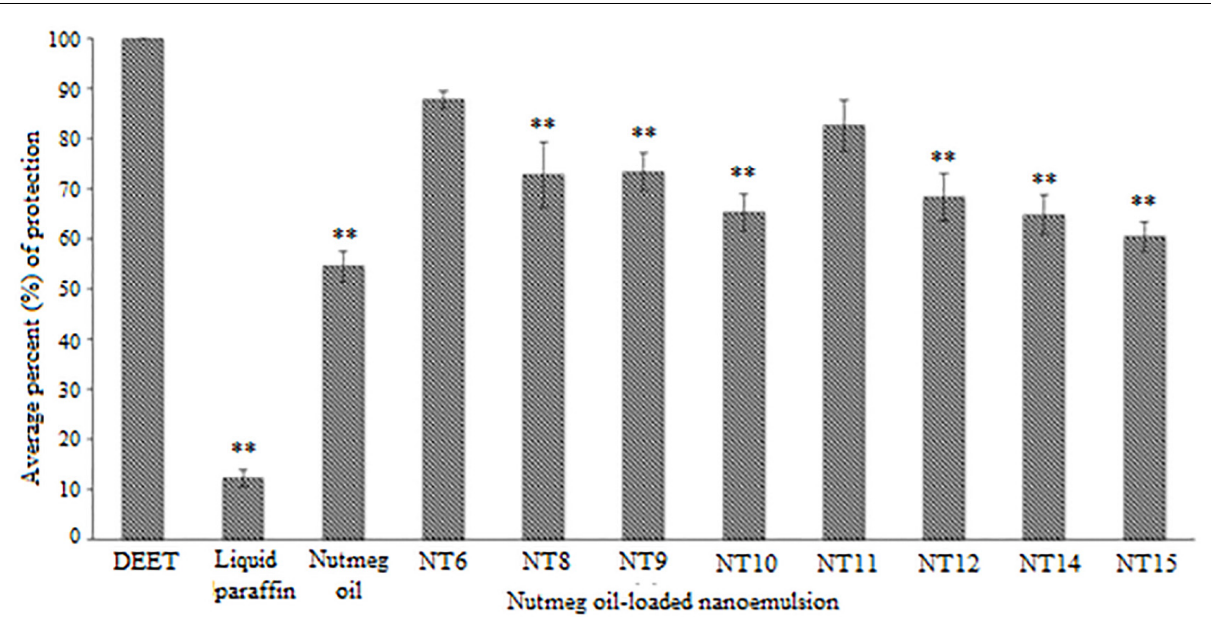

FIGURE 4 | Average percentage protection against mosquitoes provided by controls, nutmeg oil, and selected NTs for $8 \mathrm{~h}$ (Mean \pm SD, $n=3)$. ** $p<0.01$ (Dunnett $t$-test).

8 and NT 10 provided $96.67 \%$ protection. Protection provided from hour 1 to hour 8 by NT 6 ranged from 92.94 to $81.09 \%$, NT 8 (88.41 to $42.2 \%)$, NT 9 (89.35 to $49.57 \%)$, and NT 10 (86.67 to $23.33 \%$ ). Protection provided by NT 11 and NT 12 ranged from 97.3 to $68.25 \%$ and 89.44 to $31.16 \%$, respectively. NT 14 and NT 15 provided protection at $28.89 \%$ and $22.22 \%$ at hour 8 , respectively.

Figure 4 shows the average percent protection provided by the NTs to the test subjects throughout the $8 \mathrm{~h}$ test. NT 6 exhibited the greatest repellency $(87.81 \%)$ and NT 15 was least effective $(60.54 \%)$. Other NTs were recorded at $72.77 \%$ (NT 8), 73.41\% (NT 9), 65.31\% (NT 10), 82.65\% (NT 11), 68.36\% (NT 12), and $64.86 \%$ (NT 14). The average percent protection by nutmeg oil was $54.57 \%$. The protection provided by NT 6 and NT 11 did not differ significantly compared to that of the control (DEET), whereas the other NTs were significantly less effective than DEET $(p<0.01)$ (Rahman et al., 2015; Chong et al., 2018). In summary, NT 6 and NT 11 sustained their repellent activity every hour during the $8 \mathrm{~h}$ test. Therefore, these two NTs were selected for further characterization and the in vitro release study.

The selected formulated NTs exhibited higher percentage of protection compared to pure nutmeg oil. This proved that incorporating nutmeg oil into a nanoemulsion system could prolong the protection time. Although NT 6 and NT 11 could not provide greater protection than DEET (100\% throughout the $8 \mathrm{~h}$ test), the toxicity of DEET should be taken into consideration. Natural essential oil-based repellent products are safe, pleasant to the user, and environmentally sustainable. The

TABLE 2 | Zeta potential, average $\mathrm{pH}$, and viscosity of NT 6 and NT $11(n=3)$.

\begin{tabular}{lccc}
\hline Formulation & $\begin{array}{c}\text { Zeta potential } \\
(\mathbf{m V})\end{array}$ & $\begin{array}{c}\mathbf{p H} \\
(\mathbf{m e a n} \pm \mathbf{S D})\end{array}$ & $\begin{array}{c}\text { Viscosity (Pa.s) at stress } \\
\text { stress 100 Pa (mean } \pm \text { SD) }\end{array}$ \\
\hline NT 6 & -44.20 & $5.60 \pm 0.16$ & $2.49 \pm 0.49$ \\
NT 11 & -62.90 & $5.30 \pm 0.13$ & $0.09 \pm 0.02$
\end{tabular}

duration of protection against arthropod bites is important too, as essential oils contain an abundance of volatile compounds (Maia and Moore, 2011).

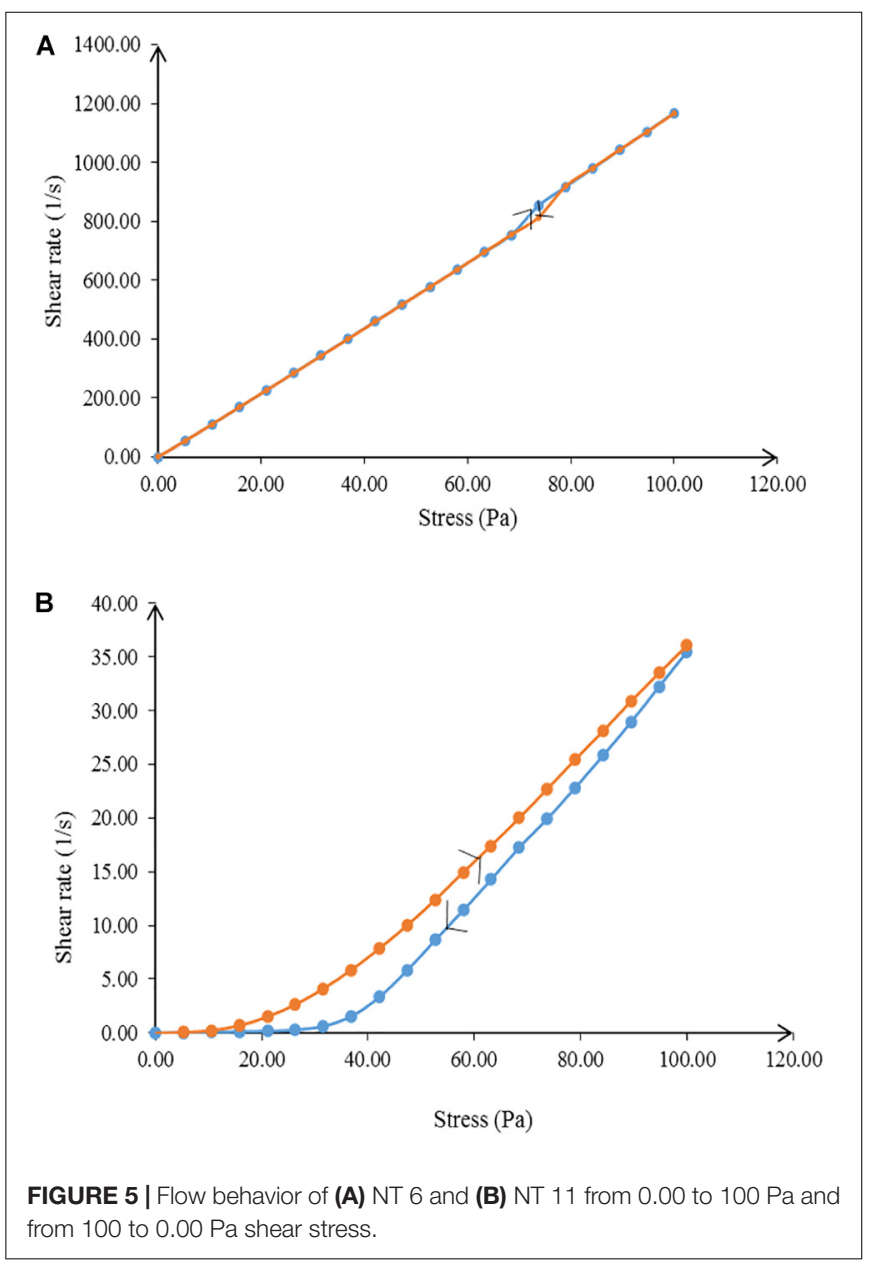



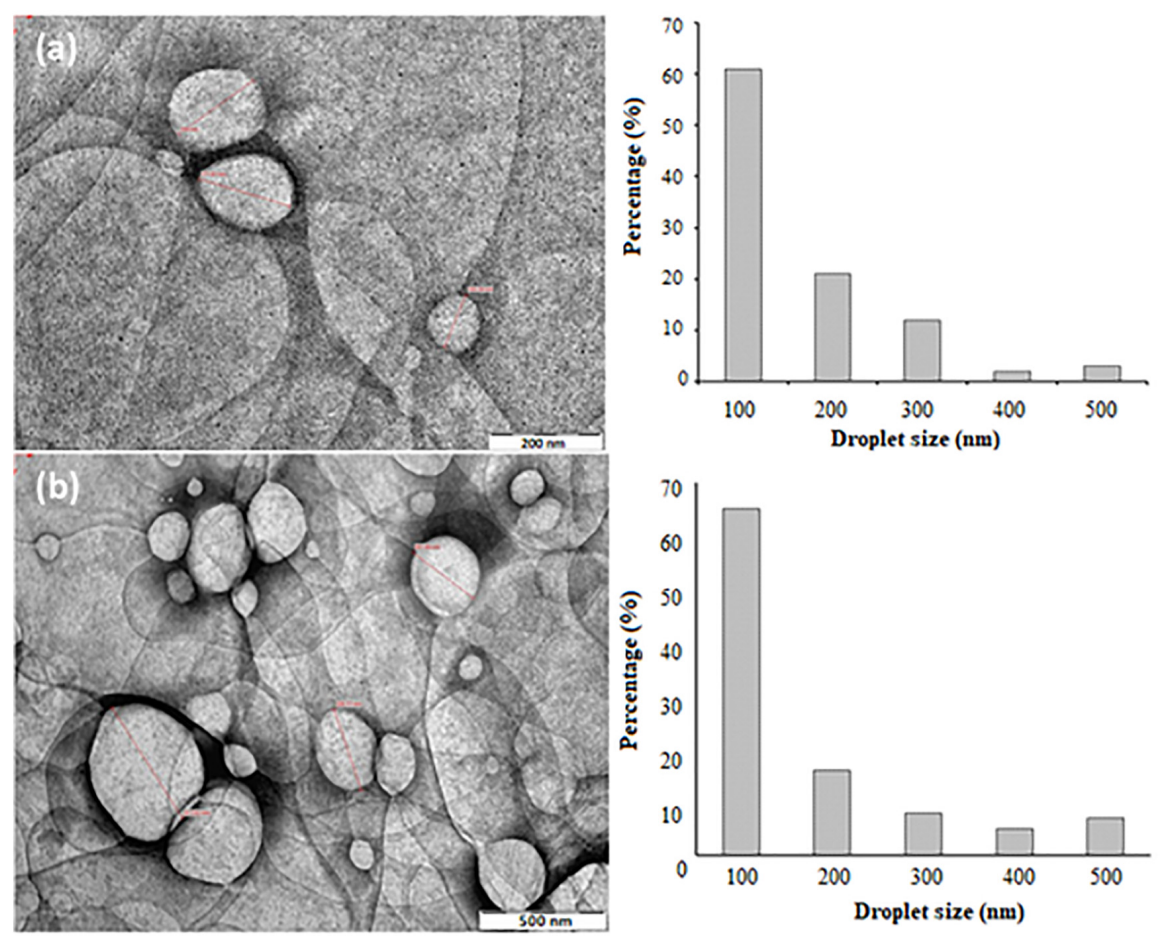

FIGURE 6 | TEM morphologies and size distributions of (a) NT 6 at 66,000 magnifications (b) NT 11 at 40,000 magnifications.

\section{Characterizations of NT 6 and NT 11}

NT 6 and NT 11 were characterized for zeta potential, pH, viscosity, rheological behavior, and surface morphology. Table 2 shows the data for zeta potential, average $\mathrm{pH}$, and viscosity of NT 6 and NT 11. The surface charge of a nanoemulsion is characterized by zeta potential, where values $>+30 \mathrm{mV}$ or $<-$ $30 \mathrm{mV}$ lead to repulsive forces between the droplets (Sari et al., 2015). The zeta potential values were -44.2 and $-62.9 \mathrm{mV}$ for NT 6 and NT 11, respectively. These high values indicated good physical stability of these nanoemulsion systems (Nuchuchua et al., 2009). High repulsive forces between the droplets of a nanoemulsion prevent aggregation in the system and provide good physical stability (Chanasattru et al., 2007). The amount of surfactant present is important because electrostatic repulsion is required to provide the surface charge for stabilization (Musa et al., 2013). Musa et al. (2013) reported that the negativity of zeta potential decreased when the amount of surfactant (lecithin) present was reduced. This repulsive electrostatic interaction between the droplets tends to hinder coalescence, thereby increasing the surface area between the droplets (Musa et al., 2013). In fact, different nanoemulsion system exhibits different particle size distribution. Nanoemulsion system of citronella oil exhibited lower droplet size with increasing surfactant concentration (but with higher glycerol concentration) (Sakulku et al., 2009). The droplet size distribution significantly determines the delivery of the system in terms of rate and the duration of release (Chen et al., 2019a,b). In this study, the negative zeta potentials recorded for NT6 and NT11 were obtained because of the presence of the non-ionic surfactant Montanov ${ }^{\circledR} 82$.
The $\mathrm{pH}$ values of NT 6 and NT 11 were $5.6 \pm 0.16$ and $5.3 \pm 0.13$, respectively. These $\mathrm{pH}$ values are suitable for topical administration to skin, as the $\mathrm{pH}$ of forearm skin is in the range of 4.2-5.9 (Borges et al., 2013). $\mathrm{pH}$ analysis is important to determine the stability and suitability of a product for topical application. In addition to $\mathrm{pH}$, viscosity of a nanoemulsion is important for physical stability (Bali et al., 2010). Viscosities of

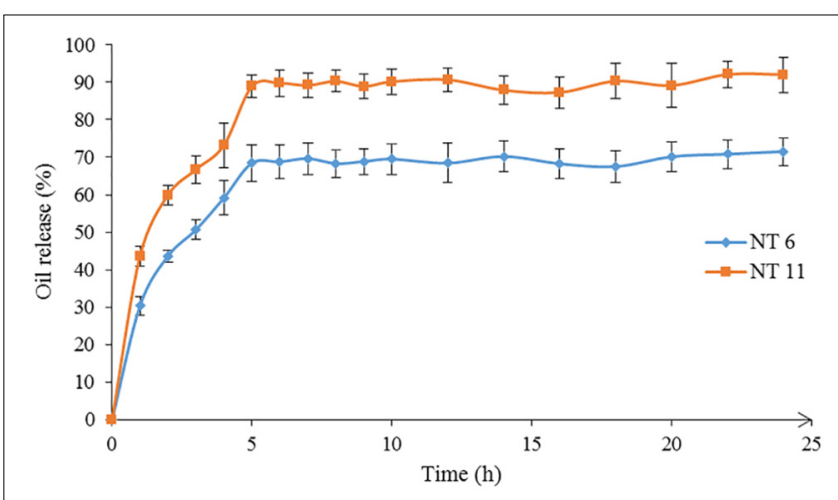

FIGURE 7 | Release profiles of NT 6 and NT 11.

TABLE 3 | In vitro release parameters of NT 6 and NT 11.

\begin{tabular}{|c|c|c|c|}
\hline Formulation & 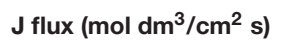 & $R^{2}$ & $k$ Value $\left(\mathrm{cm}^{2} \mathrm{~s}\right)$ \\
\hline NT 6 & 0.00112 & 0.9981 & $1.0049 \times 10^{-5}$ \\
\hline NT 11 & 0.00988 & 0.9866 & $7.8143 \times 10^{-4}$ \\
\hline
\end{tabular}




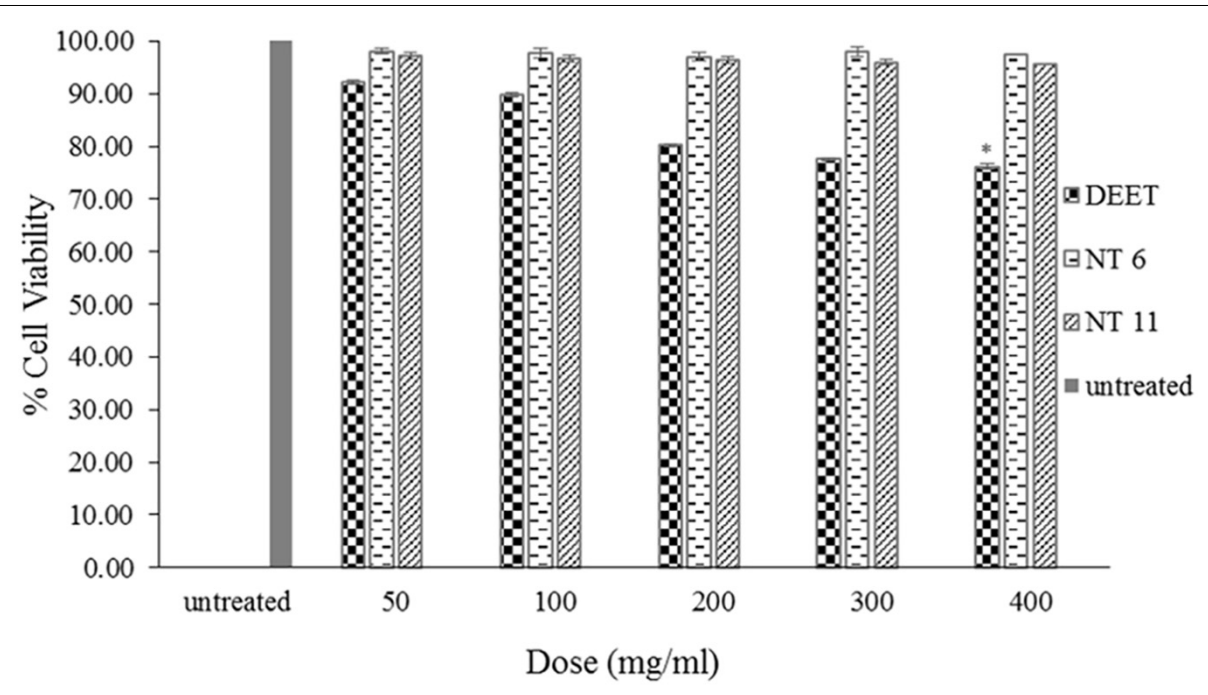

FIGURE 8 | Percentage cell viability of L929 cells after $48 \mathrm{~h}$ exposure to NT 6, NT 11, and DEET at different doses of treatment using the MTS assay (mean \pm SD, $n=3,{ }^{*} p<0.05$ (LSD test).

NT 6 and NT 11 at stress of $100 \mathrm{~Pa}$ were $2.49 \pm 0.49$ and $0.09 \pm 0.02$ Pa.s, respectively. These results show that glycerol plays a major role in increasing the viscosity of the nanoemulsion, as glycerol constitutes a greater percentage of NT 6 compared to NT 11 (Sakulku et al., 2009). In addition, the viscosity of NT 11 was less than that of NT 6 due to the water content (NT $11>$ NT 6). A higher surfactant ratio traps water in the cross-linking chain of the surfactant, which causes high viscosity of the nanoemulsion (Ghosh et al., 2013).

Rheology, or flow behavior, is an important parameter for characterizing a nanoemulsion in terms of physical stability (Vasiljevic et al., 2006). The flow of a nanoemulsion affects the release and spreadability of the essential oil to the skin surface (Khurana et al., 2013). NT 6 exhibited non-Newtonian plastic behavior, whereas NT 11 showed Newtonian flow behavior (Figure 5) due to the difference in the water ratio. Varshosaz et al. (2013) stated that the coalescence of inner water droplets in the emulsion system gave effect on the behavior of the emulsion system. A nanoemulsion with low viscosity would not be adequate for an insect repellent product meant for topical skin application because it would tend to flow easily (Khurana et al., 2013). However, this problem was solved by the addition of glycerol as the co-solvent, which increased the viscosity of the formulation.

Transmission electron microscope is another important way to analyze the surface morphology of NTs, as it provides a high resolution view of the in situ structure of the nanoemulsion (Bali et al., 2010). Figure 6 shows the surface morphologies of NT 6 and NT 11 (stained by PTA). NT 6 and NT 11 appeared bright with dark circles around the droplets, and the NTs showed both regular and irregular spherical shapes.

Droplet size of NT 6 was smaller than that of NT 11. The droplet size distribution in NT 6 and NT 11 ranged between 100 and $500 \mathrm{~nm}$, and this correlated well with the results from the Zeta Nano-ZS apparatus (Figure 6). This correlation is important because the DLS measurement was performed via dilution of the nanoemulsion (Modi and Patel, 2011). The droplet size distribution of NT 6 and NT 11 showed the highest percentage at $100 \mathrm{~nm}$ (61\% and 65\%, respectively). Bali et al. (2010) also compared droplet size using two different approaches: TEM and photon correlation spectroscopy. TEM offers the advantage of providing high resolution for structures in the nano range, which cannot be detected by classical microscopy techniques (Salvia-Trujillo et al., 2013).

\section{In vitro Release of Nutmeg Oil From NT 6 and NT 11}

The in vitro release of nutmeg oil from NT 6 and NT 11 was investigated for $24 \mathrm{~h}$ (Figure 7). $\alpha$-pinene (the major compound in nutmeg oil) was selected as the marker for this release study. The GCMS spectrum of the oil was published in Lim et al. (2019). Only $71.5 \%$ of nutmeg oil was released from NT 6 compared to $92.4 \%$ for NT 11 . Release profiles of NT 6 and NT 11 fitted the Higuchi model and yielded $R^{2}$ values of 0.9981 and 0.9866 , respectively. NT 11 had higher flux and $k$ value (release rate) than NT 6 (Table 3).

The release rate of an essential oil from a nanoemulsion is affected by viscosity, flow behavior, and water, surfactant, and cosolvent ratios in the nanoemulsion. NT 11 had a higher water ratio and exhibited higher flux and release rate compared to NT 6. Varshosaz et al. (2013) similarly reported that a metoprololloaded nanoemulsion (lecithin) with higher water ratio showed higher flux and release rate due to permeation enhancement of the desired compounds through cellulose acetate.

The slower release rate of NT 6 compared to NT 11 might be because NT 6 contained a higher percentage of surfactant $(6.25 \%)$ compared to NT 11 (3.75\%). Similarly, in a citronella oil-loaded nanoemulsion, the formulation containing $10 \%$ surfactant had a slower release rate compared to formulations with $2.5 \%$ and $5 \%$ 

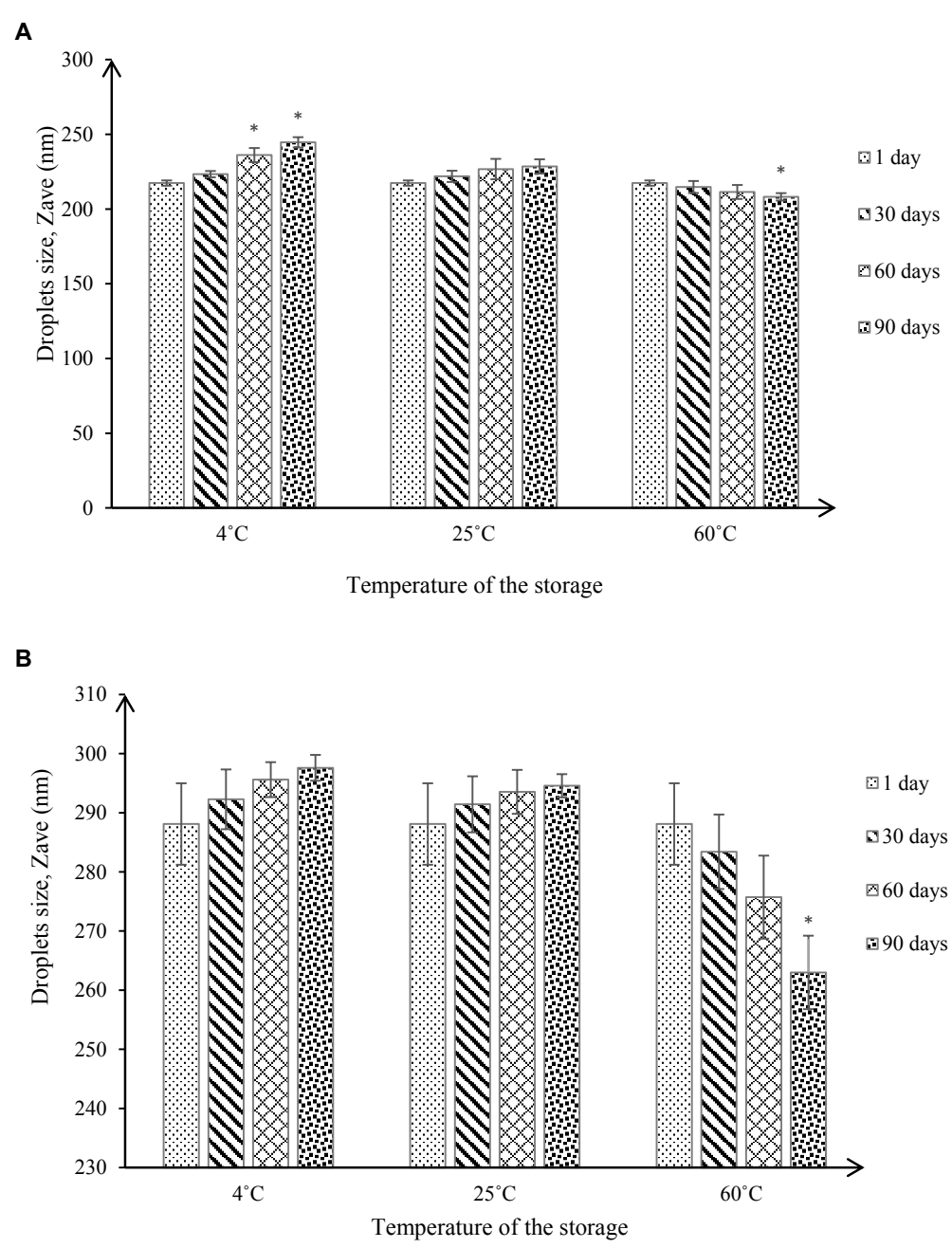

FIGURE 9 | Droplet size under different storage conditions throughout 90-day stability tests for (A) NT 6 and (B) NT 11 (mean \pm SD, $n=3,{ }^{*} p<0.05$ ).

surfactant (Sakulku et al., 2009). Therefore, surfactant content is an important factor affecting the release rate of an essential oil from a nanoemulsion system. In this study, the mobility of nutmeg oil and its release were easier at low surfactant percentage (i.e., NT 11). For NT 6, which contained a high level of glycerol, the release rate was lower because the glycerol caused the NT to be more viscous, which impacted the mobility of nutmeg oil in the carrier solution.

Despite its lower release rate, NT 6 showed greater mosquito repellent efficacy compared to NT 11. Sakulku et al. (2009) also reported that their citronella oil-loaded nanoemulsion with high percentage of glycerol and surfactant achieved a long duration of protection. These findings suggest that more viscous formulations prolong the protection time of repellent activity.

\section{Cytotoxicity of the NTs}

Testing the safety of the NTs is important, as they are intended for use as a topical application for humans. The materials included in the formulation, such as nutmeg oil and surfactant, may cause some toxicity effect (due to the presence of monoterpenes in nutmeg oil) (Shakeel et al., 2008). Therefore, NT 6 and NT 11 were subjected to cytotoxicity analysis using L929 MTS assays.

The cytotoxicity studies all were conducted using MTS assays (Chen et al., 2020a) with the same concentrations and cell lines (Figure 8). After $48 \mathrm{~h}$ of exposure to the formulations, the cell viabilities of the NT 6 group were $98.08 \%(50 \mathrm{mg} / \mathrm{mL})$, 97.7\% (100 mg/mL), 96.98\% (200 mg/mL), 98.02\% (300 mg/mL), and $97.38 \%(400 \mathrm{mg} / \mathrm{mL})$. The NT 11 group exhibited cell viabilities at $97.1 \%(50 \mathrm{mg} / \mathrm{mL}), 96.81 \%(100 \mathrm{mg} / \mathrm{mL}), 96.36 \%$ (200 mg/mL), 96.02\% (300 mg/mL), and 95.67\% (400 mg/mL). The DEET group showed cell viabilities of $92.17 \%(50 \mathrm{mg} / \mathrm{mL})$, $89.8 \%$ (100 mg/mL), 80.19\% (200 mg/mL), 77.60\% (300 mg/mL), and $76.16 \%(400 \mathrm{mg} / \mathrm{mL})$, respectively. Comparison of results of the test compounds with those of L929 cell without treatment was made using the least significance difference (LSD) test. All samples showed no significance difference $(p>0.05)$, except for DEET at the highest dose $(400 \mathrm{mg} / \mathrm{mL})(p<0.05)$.

These results indicate that NT 6 and NT 11 were not toxic to normal skin cells (Samad et al., 2018). In contrast, 


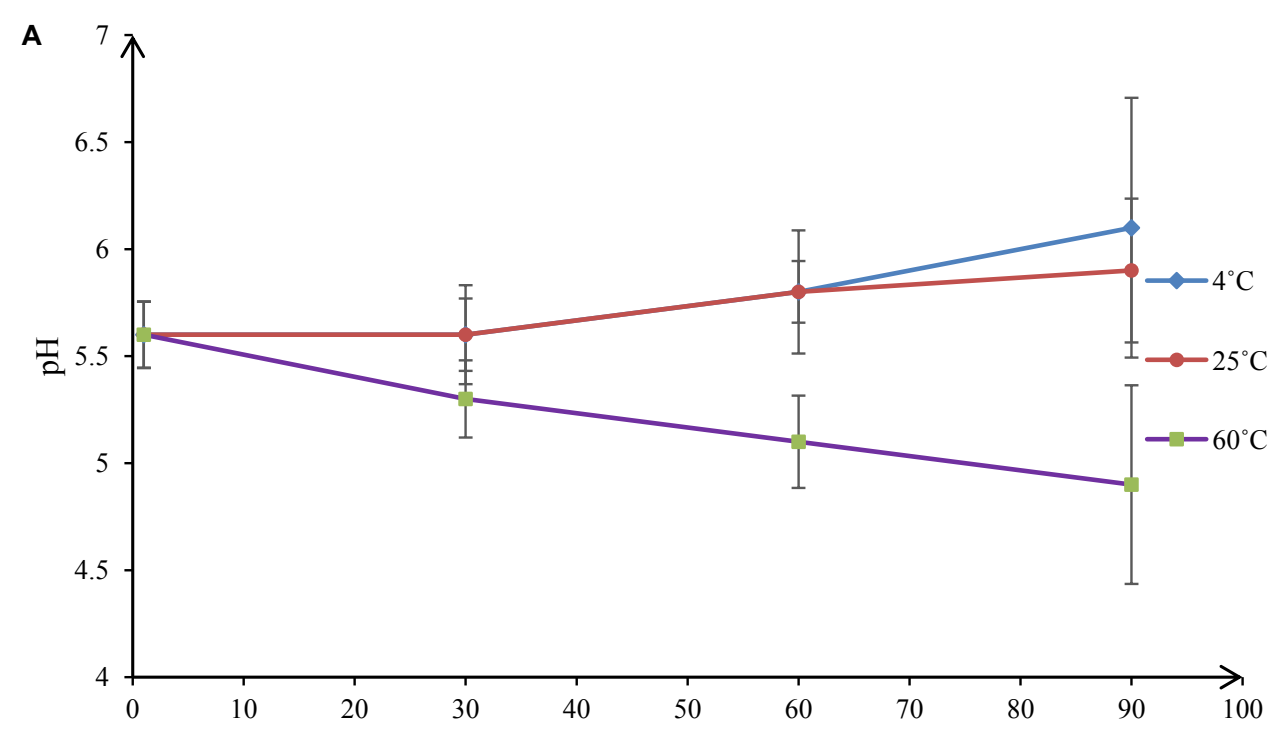

Days of storage

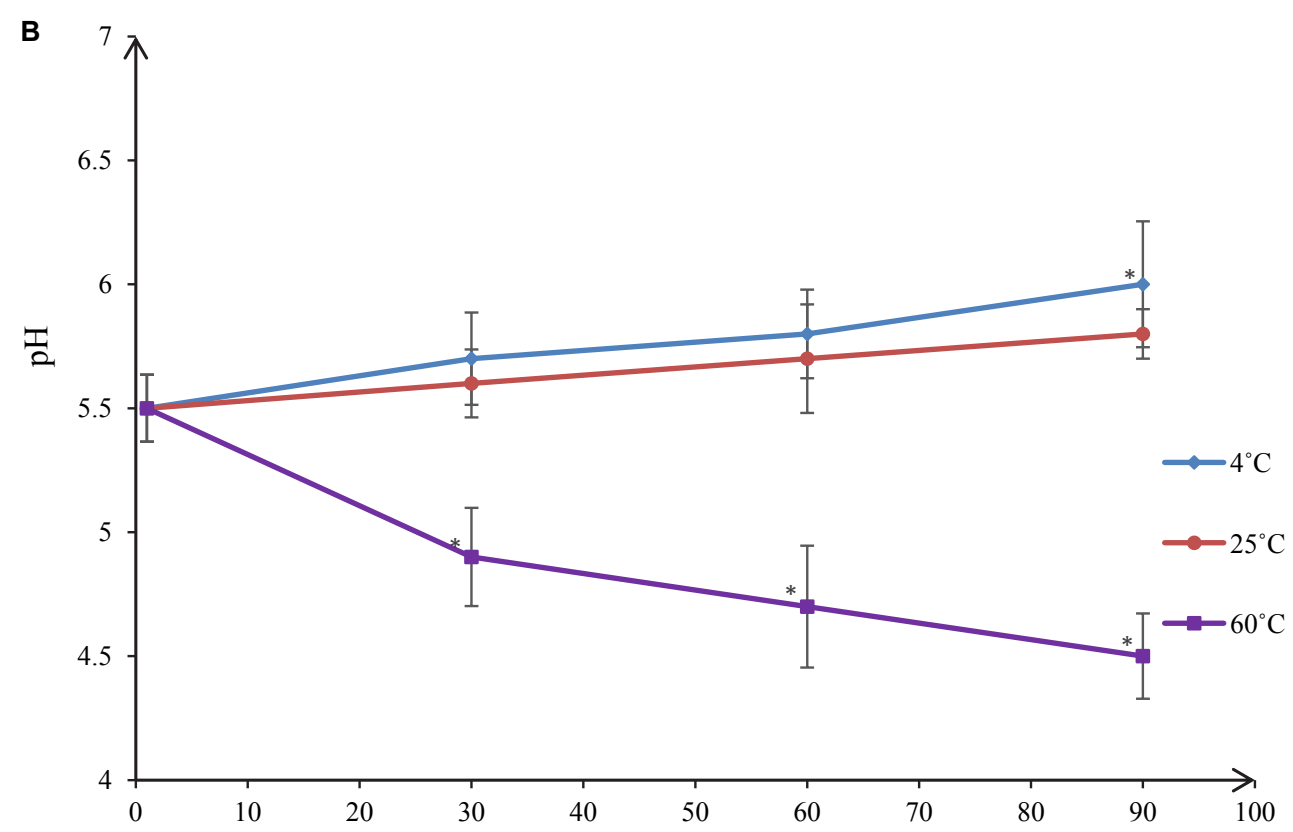

Days of storage

FIGURE $10 \mid \mathrm{pH}$ values under different storage conditions throughout 90 -day stability tests for (A) NT 6 and (B) NT 11 (mean $\left.\pm \mathrm{SD}, n=3,{ }^{*} p<0.05\right)$.

DEET at $400 \mathrm{mg} / \mathrm{mL}$ showed significant toxicity compared to the control. DEET is toxic to normal cell lines and causes skin eruption (Costanzo et al., 2007). The $\mathrm{IC}_{50}$ of the assay could not be determined because of low toxicity levels. Nerio et al. (2010) suggested that a low concentration of essential oil can reduce the toxicity and irritation effect. The amount of nutmeg oil (20\%) used in the formulations in this study had no toxic effect on L929 skin fibroblast cells. Therefore, the formulated nanoemulsions appear to pose no risk of skin irritation or toxicity for topical application.

\section{Stability of NT 6 and NT 11}

The stabilities of NT 6 and NT 11 were measured based on droplet size and $\mathrm{pH}$ values at different storage temperatures $\left(4^{\circ} \mathrm{C}\right.$, $25^{\circ} \mathrm{C}$, and $60^{\circ} \mathrm{C}$ ) and after $1,30,60$, and 90 days of storage. Droplet size measurement (Figure 9) is a good indicator of 
stability, as a rapid increase of particle size indicates low stability (Bernardi et al., 2011).

At $4^{\circ} \mathrm{C}$, the droplet size of NT 6 increased from 217.4 to $223.37 \mathrm{~nm}$ after 30 days of storage, showing no significant difference $(p>0.05$ in droplet size increase compared to day 1). After 60 and 90 days of storage, the droplet size increased to $236.13 \mathrm{~nm}$ and $244.67 \mathrm{~nm}$, respectively, which represented a significant difference $(p<0.05)$ compared to day $1(217.4 \mathrm{~nm})$. At $25^{\circ} \mathrm{C}$, the droplet size of NT 6 kept increasing to $221.9 \mathrm{~nm}$ after 30 days, $226.73 \mathrm{~nm}$ after 60 days, and $228.53 \mathrm{~nm}$ after 90 days of storage. However, these values were not significantly different from the droplet size on day 1 . In contrast, droplet size decreased from $214.77 \mathrm{~nm}$ (30 days) to $211.4 \mathrm{~nm}$ (60 days) and $208.17 \mathrm{~nm}$ (90 days) at storage temperature of $60^{\circ} \mathrm{C}$. Only the value after 90 days of storage was significantly different from that on day $1(p<0.05)$.

For NT 11, droplet size at $4^{\circ} \mathrm{C}$ increased from day $1(288.1 \mathrm{~nm})$ to day $30(292.27 \mathrm{~nm})$, then to $295.6 \mathrm{~nm}$ and $297.6 \mathrm{~nm}$ after 60 and 90 days. The same trend occurred at $25^{\circ} \mathrm{C}$ of storage, where the droplet size increased from $291.43 \mathrm{~nm}$ (30 days) to $293.53 \mathrm{~nm}$ (60 days) to $294.51 \mathrm{~nm}$ (90 days). However, the increased values at both storage temperatures did not differ significantly from the droplet size at day $1(p>0.05)$. The droplet size at $60^{\circ} \mathrm{C}$ decreased from day $1(288.1 \mathrm{~nm})$ to day $60(275.33)$, but the values did not differ significantly $(p>0.05)$. However, droplet size was $263 \mathrm{~nm}$ after 90 , which was significantly smaller than droplet size on day $1(p<0.05)$.

NT 6 and NT 11 stored at $4^{\circ} \mathrm{C}$ exhibited turbidity, but the formulation was transparent when stored at high temperature $\left(60^{\circ} \mathrm{C}\right)$. An anti-HIV nanoemulsion formulation also appeared turbid at low temperature but transparent after storage at room temperature; this was due to coagulation in the nanoemulsion system at low temperature (Kotta et al., 2014).

For NT 6 and NT 11, the increased droplet size at storage temperatures of $4^{\circ} \mathrm{C}$ and $25^{\circ} \mathrm{C}$ was still within the acceptable range for a nanoemulsion (i.e., $\leq 500 \mathrm{~nm}$ ) (Pant et al., 2014), and phase separation was not observed throughout the storage period (Bernardi et al., 2011). These results indicate good stability in the nanoemulsion system. The significant increase in droplet size for NT 6 at storage temperature of $4^{\circ} \mathrm{C}$ after 60 and 90 days might be caused by Ostwald ripening, whereby small nanoemulsion droplets become larger. In addition, droplet aggregation by flocculation and coalescence between nanoemulsion droplets may occur (Rao and McClements, 2011).

$\mathrm{pH}$ monitoring is another way to assess the stability of a nanoemulsion (Figure 10). Changes in $\mathrm{pH}$ indicate a chemical reaction (Bernardi et al., 2011). $\mathrm{pH}$ values of NT 6 were 5.6 (day 1), 5.6 (day 30), 5.8 (day 60), and 6.1 (day 90 ) at $4^{\circ} \mathrm{C}$. Values at $25^{\circ} \mathrm{C}$ were 5.6 (day 1 ), 5.6 (day 30), 5.8 (day 60 ), and 5.9 (day $90)$. These values did not differ significantly from those at day 1 $\left(p>0.05\right.$ ). At $60^{\circ} \mathrm{C}, \mathrm{pH}$ decreased to 5.3 (day 30), 5.1 (day 60), and 4.9 (day 90 ). The $\mathrm{pH}$ value at day 90 differed significantly from that at day $1(p<0.05)$.

The $\mathrm{pH}$ values of NT 11 at $4^{\circ} \mathrm{C}$ storage temperatures were 5.5 (day 1), 5.7 (day 30), 5.8 (day 60), and 6.0 (day 90 ). At $25^{\circ} \mathrm{C}$ they were 5.5 (day 1), 5.6 (day 30), 5.7 (day 60), and 5.8 (day 90). For $4^{\circ} \mathrm{C}$, the only significant difference detected was between the values at day 90 and day $1(p<0.05)$. No significant difference was detected between the control and any time point at $25^{\circ} \mathrm{C}$ $(p>0.05)$. At $60^{\circ} \mathrm{C}$ storage temperature, the $\mathrm{pH}$ decreased from 5.5 to 4.5 over the course of 90 days, and the values at days 30,60 , and 90 all differed significantly from the value at day $1(p<0.05)$.

These results show that the pH values of NT 6 and NT 11 were stable throughout 90 days of storage at temperatures of $4^{\circ} \mathrm{C}$ and $25^{\circ} \mathrm{C}$. The range of reported $\mathrm{pH}$ values was acceptable for topical administration (5.4-6.9) (Borges et al., 2013). In summary, droplet size and $\mathrm{pH}$ of both NT 6 and NT 11 were stable at storage temperatures of $4^{\circ} \mathrm{C}$ and $25^{\circ} \mathrm{C}$ but not at $60^{\circ} \mathrm{C}$. NT 6 and NT 11 are currently stored at the Herbarium Unit, Integrative Medicine Cluster, IPPT, USM with voucher numbers MF-004-NT6 and MF-004-NT11, respectively.

\section{CONCLUSION}

Incorporating of essential oil using a nanoemulsion system can be used to control the release of the oil and prolong the insect repelling effect. In this study, nutmeg oil-loaded nanoemulsions were formulated and tested for their effectiveness as mosquito repellents.

Previous studies of nutmeg, basil, and peppermint oils and their combinations indicated that nutmeg oil was the best at providing protection against mosquitoes for SD rats. Therefore, nutmeg oil was used in this study to formulate essential oil-loaded nanoemulsions to develop an effective controlled release natural repellent formulation.

NT 6 and NT 11 formed desirable droplet sizes $(<500 \mathrm{~nm})$ with PDI values $<0.5$. Zeta potentials of the NTs also were within the acceptable range $(>-30 \mathrm{mV})$. $\mathrm{pH}$ values ranged from 4.2 to 5.9 , which is suitable for topical application. Viscosities of these NTs were affected by the amount of water and glycerol in the formulation. Release rates of nutmeg oil for NT 6 and NT 11 were $1.0049 \times 10^{-5} \mathrm{~cm}^{2} \mathrm{~s}$ and $7.8143 \times 10^{-4} \mathrm{~cm}^{2} \mathrm{~s}$, respectively. The amount of surfactant used to produce NT 6 and NT 11 was less than $10 \%$. The low percentage of surfactant used meets sensory, regulatory, and economic objectives. The preparation of NTs using a high speed stirring homogenizer and sonication tools produced stable nanoemulsion systems, which would be economically effective for larger scale production. In conclusion, NT 6 and NT 11 provided high mosquito repellent efficacy compared to nutmeg oil only and may prove to be useful alternatives for insect repellent products in the future.

\section{DATA AVAILABILITY STATEMENT}

All datasets generated for this study are included in the article/supplementary material.

\section{ETHICS STATEMENT}

All animal procedures used were in strict accordance with animal care protocols, and all experimental protocols were approved 
by the Universiti Sains Malaysia Animal Ethics Committee [USM/Animal Ethics Approval/2013/(85) (441)].

\section{AUTHOR CONTRIBUTIONS}

All the authors were involved in the designing of the experiments. Additionally, MM, HC, and NM conducted the experiments. MR, SS, YY, and CT analyzed and interpreted the data. VL and MM wrote the manuscript. VL supervised the entire study.

\section{REFERENCES}

Adeniran, O. I., and Fabiyi, E. (2012). A cream formulation of an effective mosquito repellent: a topical product from lemongrass oil (Cymbopogon citratus) Stapf. J. Nat. Prod. Plant. Resour. 2, 322-327.

Assi, R. A., Darwis, Y., Abdulbaqi, I. M., Khan, A. A., Lim, V., and Laghari, M. H. (2017). Morinda citrifolia (Noni): a comprehensive review on its industrial uses, pharmacological activities, and clinical trials. Arab. J. Chem. 10, 691-707. doi: 10.1016/j.arabjc.2015.06.018

Ayub, A. D., Chiu, H. I., Mat Yusuf, S. N. A., Abd Kadir, E., Ngalim, S. H., and Lim, V. (2019). Biocompatible disulphide cross-linked sodium alginate derivative nanoparticles for oral colon- targeted drug delivery. Artif. Cells Nanomed. Biotechnol. 47, 353-369. doi: 10.1080/21691401.2018.1557672

Azeem, M., Zaman, T., Tahir, M., Haris, A., Iqbal, Z., Binyameen, M., et al. (2019). Chemical composition and repellent activity of native plants essential oils against dengue mosquito, Aedes aegypti. Ind. Crops Products 140:111609. doi: 10.1016/j.indcrop.2019.111609

Bali, V., Ali, M., and Ali, J. (2010). Study of surfactant combinations and development of a novel nanoemulsion for minimising variations in bioavailability of ezetimibe. Colloids Surf. B Biointerfaces 76, 410-420. doi: 10.1016/j.colsurfb.2009.11.021

Bernardi, D. S., Pereira, T. A., Maciel, N. R., Bortoloto, J., Viera, G. S., Oliveira, G. C., et al. (2011). Formation and stability of oil-in-water nanoemulsions containing rice bran oil: in vitro and in vivo assessments. J. Nanobiotechnol. 9:44. doi: 10.1186/1477-3155-9-44

Bissinger, B. W., and Roe, R. M. (2010). Tick repellents: past, present, and future. Pestic. Biochem. Physiol. 96, 63-79. doi: 10.1016/j.pestbp.2009.09.010

Borges, V. R., de, A., Simon, A., Sena, A. R. C., Cabral, L. M., and de Sousa, V. P. (2013). Nanoemulsion containing dapsone for topical administration: a study of in vitro release and epidermal permeation. Int. J. Nanomed. 8, 535-544. doi: $10.2147 /$ IJN.S39383

Borhade, V., Pathak, S., Sharma, S., and Patravale, V. (2012). Clotrimazole nanoemulsion for malaria chemotherapy. Part I: preformulation studies, formulation design and physicochemical evaluation. Int. J. Pharm. 431, 138148. doi: 10.1016/j.ijpharm.2011.12.040

Carbone, C., Campisi, A., Musumeci, T., Raciti, G., Bonfanti, R., and Puglisi, G. (2014). FA-loaded lipid drug delivery systems: preparation, characterization and biological studies. Eur. J. Pharm. Sci. 52, 12-20. doi: 10.1016/j.ejps.2013.10.003

Chanasattru, W., Decker, E. A., Julian, and McClements, D. (2007). Inhibition of droplet flocculation in globular-protein stabilized oil-in-water emulsions by polyols. Food Res. Int. 40, 1161-1169. doi: 10.1016/j.foodres.2007.06.012

Chen, L., Gnanaraj, C., Arulselvan, P., El-Seedi, H., and Teng, H. (2019a). A review on advanced microencapsulation technology to enhance bioavailability of phenolic compounds: based on its activity in the treatment of Type 2 diabetes. Trends Food Sci. Technol. 85, 149-162. doi: 10.1016/j.tifs.2018. 11.026

Chen, L., Lin, X., and Teng, H. (2020a). Emulsions loaded with dihydromyricetin enhance its transport through Caco-2 monolayer and improve anti-diabetic effect in insulin resistant HepG2 cell. J. Funct. Foods 64:103672. doi: 10.1016/ j.jff.2019.103672

Chen, L., Lin, X., Xu, X., Chen, Y., Li, K., Fan, X., et al. (2019b). Selfnano-emulsifying formulation of Sonchus oleraceus Linn for improved stability: implications for phenolics degradation under in vitro gastrointestinal digestion: food grade drug delivery system for crude extract but

\section{FUNDING}

This work was supported by the Ministry of Higher Education, Malaysia, Fundamental Research Grant Scheme (FRGS) (203/CIPPT/6711684) entitled Novel thiolated alginatePLGA aptamer-functionalized targeting nanoparticle as multi drug carrier: Mechanism of cytotoxicity, cellular uptake and multi drug resistance, USM Short Term Grant (304/CIPPT/6312019), and USM Bridging Grant (304.CIPPT.6316264).

not single compound. J. Funct. Foods 53, 28-35. doi: 10.1016/j.jff.2018. 12.009

Chen, L., Lin, X., Xu, X., Wang, L., Teng, H., and Cao, H. (2020b). Antiinflammatory effect of self-emulsifying delivery system containing Sonchus oleraceus Linn extract on streptozotocin-induced diabetic rats. Food Chem. Toxicol. 135:110953. doi: 10.1016/j.fct.2019.11 0953

Chong, H. W., Rezaei, K., Chew, B. L., and Lim, V. (2018). Chemometric profiling of Clinacanthus nutans leaves possessing antioxidant activities using ultravioletvisible spectrophotometry. Chiang Mai J. Sci. 45, 1-12.

Costanzo, S. D., Watkinson, A. J., Murby, E. J., Kolpin, D. W., and Sandstrom, M. W. (2007). Is there a risk associated with the insect repellent DEET (N,Ndiethyl-m-toluamide) commonly found in aquatic environments? Sci. Total Environ. 384, 214-220. doi: 10.1016/j.scitotenv.2007.05.036

Devarajan, V., and Ravichandran, V. (2011). Nanoemulsions as modified drug delivery tool. Pharm. Glob. Int. J. Compr. Pharm. 2, 1-6.

Divsalar, A., Saboury, A. A., Nabiuni, M., Zare, Z., Kefayati, M. E., and Seyedarabi, A. (2012). Characterization and side effect analysis of a newly designed nanoemulsion targeting human serum albumin for drug delivery. Colloids Surf. B Biointerfaces 98, 80-84. doi: 10.1016/j.colsurfb.2012.04.036

Donsì, F., Annunziata, M., Vincensi, M., and Ferrari, G. (2012). Design of nanoemulsion-based delivery systems of natural antimicrobials: effect of the emulsifier. J. Biotechnol. 159, 342-350. doi: 10.1016/j.jbiotec.2011. 07.001

Fernandez, P., André, V., Rieger, J., and Kühnle, A. (2004). Nano-emulsion formation by emulsion phase inversion. Colloids Surf. A Physicochem. Eng. Asp. 251, 53-58. doi: 10.1016/j.colsurfa.2004.09.029

Ghosh, V., Mukherjee, A., and Chandrasekaran, N. (2013). Ultrasonic emulsification of food-grade nanoemulsion formulation and evaluation of its bactericidal activity. Ultrason. Sonochem. 20, 338-344. doi: 10.1016/j.ultsonch.2012.08.010

Ghozali, S. Z. L., Lim, V., and Ahmad, N. H. (2015). Biosynthesis and characterization of silver nanoparticles using Catharanthus roseus leaf extract and its proliferative effects on cancer cell lines. J. Nanomed. Nanotechnol. 6:1000305. doi: 10.4172/2157-7439.1000305

Govindarajan, M. (2010). Larvicidal and repellent activities of Sida acuta Burm. F. (Family: Malvaceae) against three important vector mosquitoes. Asian Pac. J. Trop. Med. 3, 691-695. doi: 10.1016/S1995-7645(10)60 167-8

Gupta, D. K., Chouhan, M., Mangalawat, S., and Gupta, R. (2013). A review on plant essential oils as mosquito repellent. J. Curr. Sci. 20, 741-747.

Hanan, N. A., Chiu, H. I., Ramachandran, M. R., Tung, W. H., Mohamad Zain, N. N., Yahaya, N., et al. (2018). Cytotoxicity of plant-mediated synthesis of metallic nanoparticles: a systematic review. Int. J. Mol. Sci. 19:1725. doi: 10. 3390/ijms19061725

Hang Chio, E., and Yang, E. C. (2008). A bioassay for natural insect repellents. J. Asia. Pac. Entomol. 11, 225-227. doi: 10.1016/j.aspen.2008.08.002

Iyer, P., and Makris, S. (2010). "Developmental and reproductive toxicology of pesticides," in Hayes' Handbook of Pesticide Toxicology, ed. R. Krieger, (San Diego, CA: Academic Press), 381-440. doi: 10.1016/B978-0-12-374367$1.00012-4$

Jafari, S. M., He, Y., and Bhandari, B. (2007). Optimization of nano-emulsions production by microfluidization. Eur. Food Res. Technol. 225, 733-741. doi: 10.1007/s00217-006-0476-9 
Khurana, S., Jain, N. K., and Bedi, P. M. S. (2013). Nanoemulsion based gel for transdermal delivery of meloxicam: physico-chemical, mechanistic investigation. Life Sci. 92, 383-392. doi: 10.1016/j.lfs.2013.01.005

Kotta, S., Khan, A. W., Ansari, S. H., Sharma, R. K., and Ali, J. (2014). Anti HIV nanoemulsion formulation: optimization and in vitro-in vivo evaluation. Int. J. Pharm. 462, 129-134. doi: 10.1016/j.ijpharm.2013.12.038

Leong, T. S. H., Wooster, T. J., Kentish, S. E., and Ashokkumar, M. (2009). Minimising oil droplet size using ultrasonic emulsification. Ultrason. Sonochem. 16, 721-727. doi: 10.1016/j.ultsonch.2009.02.008

Lim, K. T., Lim, V., and Chin, J. H. (2012). Subacute oral toxicity study of ethanolic leaves extracts of Strobilanthes crispus in rats. Asian Pac. J. Trop. Biomed. 2, 948-952. doi: 10.1016/S2221-1691(13)60005-2

Lim, V., Khiang Peh, K., and Sahudin, S. (2013). Synthesis, characterisation, and evaluation of a cross-linked disulphide amide-anhydride-containing polymer based on cysteine for colonic drug delivery. Int. J. Mol. Sci. 14, 24670-24691. doi: 10.3390/ijms141224670

Lim, V., Mohd Narawi, M., Chiu, H. I., Tung, W. H., Tan, J. J., and Lee, C. K. (2019). Selected essential oils as repellents against aedes aegypti: validation of the bioconstituents using gas chromatography. J. Essential Oil Bearing Plants 22, 1058-1073. doi: 10.1080/0972060X.2019.1661796

Lim, V., Yap, C., Chong, H., Shukkoor, M., and Priya, M. (2015). Antimicrobial evaluation and GC-MS analysis of Strobilanthes crispus ethanolic leaf extract. Eur. J. Med. Plants 10, 1-8. doi: 10.9734/ejmp/2015/20075

Maia, M. F., and Moore, S. J. (2011). Plant-based insect repellents: a review of their efficacy, development and testing. Malar. J. 10:S11. doi: 10.1186/1475-2875-10S1-S11

Maji, T. K., and Hussain, M. R. (2009). Microencapsulation of Zanthoxylum limonella oil (ZLO) in genipin crosslinked chitosan-gelatin complex for mosquito repellent application. J. Appl. Polym. Sci. 2, 779-785. doi: 10.1002/ app. 29001

Modi, J. D., and Patel, J. K. (2011). Nanoemulsion-based gel formulation of aceclofenac for topical delivery. Int. J. Pharm. Pharm. Sci. Res. 1, 6-12.

Musa, S. H., Basri, M., Masoumi, H. R. F., Karjiban, R. A., Malek, E. A., Basri, H., et al. (2013). Formulation optimization of palm kernel oil esters nanoemulsionloaded with chloramphenicol suitable for meningitis treatment. Colloids Surf. B Biointerfaces 112, 113-119. doi: 10.1016/j.colsurfb.2013.07.043

Nerio, L. S., Olivero-Verbel, J., and Stashenko, E. (2010). Repellent activity of essential oils: a review. Bioresour. Technol. 101, 372-378. doi: 10.1016/j.biortech. 2009.07.048

Nuchuchua, O., Sakulku, U., Uawongyart, N., Puttipipatkhachorn, S., Soottitantawat, A., and Ruktanonchai, U. (2009). In vitro characterization and mosquito (Aedes aegypti) repellent activity of essential-oils-loaded nanoemulsions. AAPS PharmSciTech 10, 1234-1242. doi: 10.1208/s12249-0099323-1

Oshaghi, M. A., Ghalandari, R., Vatandoost, H., Shayeghi, M., Kamali-Nejad, M., Tourabi-Khaledi, H., et al. (2003). Repellent effect of extracts and essential oils of Citrus limon (Rutaceae) and Melissa officinalis (Labiatae) against main malaria vector, Anopheles stephensi (Diptera: Culicidae). Iran. J. Public Health 32, 47-52.

Pant, M., Dubey, S., Patanjali, P. K., Naik, S. N., and Sharma, S. (2014). Insecticidal activity of eucalyptus oil nanoemulsion with karanja and jatropha aqueous filtrates. Int. Biodeterior. Biodegrad. 91, 119-127. doi: 10.1016/j.ibiod.2013. 11.019

Poobalan, K., Lim, V. L., Kamal, N. N. S. N. M., Yusoff, N. A., Khor, K. Z., and Samad, N. A. (2018). Effects of ultrasound assisted sequential extraction (UASE) of Moringa oleifera leaves extract on MCF 7 human breast cell line. Malaysian J. Med. Heal. Sci. 14, 102-106.

Ragelle, H., Crauste-Manciet, S., Seguin, J., Brossard, D., Scherman, D., Arnaud, P., et al. (2012). Nanoemulsion formulation of fisetin improves bioavailability and antitumour activity in mice. Int. J. Pharm. 427, 452-459. doi: 10.1016/j.ijpharm. 2012.02.025

Rahman, M. Z. F. A., Chong, H. W., and Lim, V. (2015). UV-visible metabolomics approach for the determination of selected adulterants in claimed premixed coffee. Malaysian J. Med. Heal. Sci. 14, 147-152.

Rao, J., and McClements, D. J. (2011). Food-grade microemulsions, nanoemulsions and emulsions: fabrication from sucrose monopalmitate \& lemon oil. Food Hydrocoll. 25, 1413-1423. doi: 10.1016/j.foodhyd.2011.02.004
Rocha-Filho, P. A., Maruno, M., Oliveira, B., Bernardi, D. S., Gumiero, V. C., and Pereira, T. A. (2014). Nanoemulsions as a vehicle for drugs and cosmetics. Nanosci. Technol. Open Access 1, 1-4. doi: 10.15226/2374-8141/1/1/00105

Saberi, A. H., Fang, Y., and McClements, D. J. (2013). Effect of glycerol on formation, stability, and properties of vitamin-E enriched nanoemulsions produced using spontaneous emulsification. J. Colloid Interface Sci. 411, 105113. doi: $10.1016 /$ j.jcis.2013.08.041

Sakulku, U., Nuchuchua, O., Uawongyart, N., Puttipipatkhachorn, S., Soottitantawat, A., and Ruktanonchai, U. (2009). Characterization and mosquito repellent activity of citronella oil nanoemulsion. Int. J. Pharm. 372, 105-111. doi: 10.1016/j.ijpharm.2008.12.029

Salvia-Trujillo, L., Rojas-Graü, A., Soliva-Fortuny, R., and Martín-Belloso, O. (2015). Physicochemical characterization and antimicrobial activity of food-grade emulsions and nanoemulsions incorporating essential oils. Food Hydrocoll. 43, 547-556. doi: 10.1016/j.foodhyd.2014.07.012

Salvia-Trujillo, L., Rojas-Graü, M. A., Soliva-Fortuny, R., and Martín-Belloso, O. (2013). Effect of processing parameters on physicochemical characteristics of microfluidized lemongrass essential oil-alginate nanoemulsions. Food Hydrocoll. 30, 401-407. doi: 10.1016/j.foodhyd.2012.07.004

Samad, N. A., Nur, N., Nik, S., Kamal, M., Yahaya, N., Bin, M. Y., et al. (2018). Ethnobotanical, phytochemical, and pharmacological aspects of Melastoma sp. Malaysian J. Med. Heal. Sci. 14, 153-163.

San Martin-González, M. F., Roach, A., and Harte, F. (2009). Rheological properties of corn oil emulsions stabilized by commercial micellar casein and high pressure homogenization. LWT - Food Sci. Technol. 42, 307-311. doi: 10.1016/j.lwt.2008. 04.005

Sari, T. P., Mann, B., Kumar, R., Singh, R. R. B., Sharma, R., Bhardwaj, M., et al. (2015). Preparation and characterization of nanoemulsion encapsulating curcumin. Food Hydrocoll. 43, 540-546. doi: 10.1016/j.foodhyd.2014. 07.011

Shakeel, F., Baboota, S., Ahuja, A., Ali, J., Aqil, M., and Shafiq, S. (2008). Nanoemulsions as vehicles for transdermal delivery of aceclofenac. AAPS PharmSciTech 8, 91-98. doi: 10.1208/pt0804104

Solomon, B., Sahle, F. F., Gebre-Mariam, T., Asres, K., and Neubert, R. H. H. (2012). Microencapsulation of citronella oil for mosquito-repellent application: formulation and in vitro permeation studies. Eur. J. Pharm. Biopharm. 80, 61-66. doi: 10.1016/j.ejpb.2011.08.003

Subramaniam, S. (2016). Press Statement by Minister of Health Malaysia: Current Zika Situation in Malaysia 7th September 2016. Available at: http://www.moh. gov.my/english.php/database_stores/attach_download/337/450/.

Sugumar, S., Ghosh, V., Nirmala, M. J., Mukherjee, A., and Chandrasekaran, N. (2014). Ultrasonic emulsification of eucalyptus oil nanoemulsion: antibacterial activity against Staphylococcus aureus and wound healing activity in Wistar rats. Ultrason. Sonochem. 21, 1044-1049. doi: 10.1016/j.ultsonch.2013. 10.021

Tan, J. J., Azmi, S. M., Yong, Y. K., Cheah, H. L., Lim, V., Sandai, D., et al. (2014). Tualang honey improves human corneal epithelial progenitor cell migration and cellular resistance to oxidative stress in vitro. PLOS ONE 9:e96800. doi: 10.1371/journal.pone.0096800

Tang, S. Y., Manickam, S., Wei, T. K., and Nashiru, B. (2012). Formulation development and optimization of a novel Cremophore EL-based nanoemulsion using ultrasound cavitation. Ultrason. Sonochem. 19, 330-345. doi: 10.1016/j. ultsonch.2011.07.001

Teng, H., and Chen, L. (2017). $\alpha$-Glucosidase and $\alpha$-amylase inhibitors from seed oil: a review of liposoluble substance to treat diabetes. Crit. Rev. Food Sci. Nutr. 57, 3438-3448. doi: 10.1080/10408398.2015.1129309

Varshosaz, J., Andalib, S., Tabbakhian, M., and Ebrahimzadeh, N. (2013). Development of lecithin nanoemulsion based organogels for permeation enhancement of metoprolol through rat skin. J. Nanomater. 2013, 1-10. doi: $10.1155 / 2013 / 139437$

Vasiljevic, D., Parojcic, J., Primorac, M., and Vuleta, G. (2006). An investigation into the characteristics and drug release properties of multiple W/O/W emulsion systems containing low concentration of lipophilic polymeric emulsifier. Int. J. Pharm. 309, 171-177. doi: 10.1016/j.ijpharm.2005.11.034

Wang, L., Li, X., Zhang, G., Dong, J., and Eastoe, J. (2007). Oil-in-water nanoemulsions for pesticide formulations. J. Colloid Interface Sci. 314, 230-235. doi: 10.1016/j.jcis.2007.04.079 
Wissing, S. A., and Müller, R. H. (2002). Solid lipid nanoparticles as carrier for sunscreens: in vitro release and in vivo skin penetration. J. Control. Release 81, 225-233. doi: 10.1016/S0168-3659(02)00056- 1

Yakop, F., Abd Ghafar, S. A., Yong, Y. K., Saiful Yazan, L., Mohamad Hanafiah, R., Lim, V., et al. (2018). Silver nanoparticles Clinacanthus nutans leaves extract induced apoptosis towards oral squamous cell carcinoma cell lines. Artif. Cells Nanomed. Biotechnol. 46, 131-139. doi: 10.1080/21691401.2018.1452750

Yuan, Y., Gao, Y., Zhao, J., and Mao, L. (2008). Characterization and stability evaluation of $\beta$-carotene nanoemulsions prepared by high pressure homogenization under various emulsifying conditions. Food Res. Int. 41, 61-68. doi: 10.1016/j.foodres.2007.09.006
Conflict of Interest: The authors declare that the research was conducted in the absence of any commercial or financial relationships that could be construed as a potential conflict of interest.

Copyright (c) 2020 Mohd Narawi, Chiu, Yong, Mohamad Zain, Ramachandran, Tham, Samsurrijal and Lim. This is an open-access article distributed under the terms of the Creative Commons Attribution License (CC BY). The use, distribution or reproduction in other forums is permitted, provided the original author(s) and the copyright owner(s) are credited and that the original publication in this journal is cited, in accordance with accepted academic practice. No use, distribution or reproduction is permitted which does not comply with these terms. 